\title{
Transitional B cells involved in autoimmunity and their impact on neuroimmunological diseases
}

Yang Zhou ${ }^{1+}$, Ying Zhang ${ }^{1+}$, Jinming Han ${ }^{1}$, Mengge Yang ${ }^{1}$, Jie Zhu ${ }^{1,2}$ and Tao Jin $^{1 *}$ (D)

\begin{abstract}
Transitional B cells (TrB cells) represent a crucial link between immature B cells in the bone marrow and mature peripheral B cells. Although $\operatorname{TrB}$ cells represent one of the regulatory B cell subpopulations in healthy individuals, the frequency of $\mathrm{CD} 24^{\mathrm{hi}} \mathrm{CD} 38^{\mathrm{hi}} \mathrm{Tr} \mathrm{r}$ cells in circulation may be altered in individuals with autoimmune diseases, such as multiple sclerosis, neuromyelitisoptica spectrum disorders, systemic lupus erythematosus, Sjögren's syndrome, rheumatoid arthritis, systemic sclerosis, and juvenile dermatomyositis. Although TrB cells play regulatory roles under inflammatory conditions, consequences of their functional impairment vary across autoimmune diseases. Since the origin, development, and function of TrB cells, especially in humans, remain unclear and controversial, this review aimed to discuss the characteristics of TrB cells at steady state and explore their role in various immune diseases, including autoimmune rheumatic diseases and neuroimmunological diseases.
\end{abstract}

Keywords: Transitional B cells, TrB-associated molecules, Autoimmune rheumatic diseases, Multiple sclerosis, Neuromyelitisoptica spectrum disorders

\section{Introduction}

B cells are centrally involved in the pathogenesis of autoimmunity, exerting diverse effects such as contributing to $\mathrm{T}$ cell activation through antibody production and antigen presentation. B cells also regulate immunological functions by suppressing $\mathrm{T}$ cell proliferation and producing pro-inflammatory cytokines, such as interferon-gamma (IFN- $\gamma$ ), tumor necrosis factor- $\alpha$ (TNF- $\alpha)$, and interleukin (IL)-17 [1, 2].

Transitional B cells (TrB cells) are bone marrowderived, immature $\mathrm{B}$ cells, which are also considered to be precursors of mature B cells [3, 4]. In mice, approximately $10 \%$ of immature B cells overcome negative selection in the bone marrow and get transferred to the spleen

\footnotetext{
*Correspondence: drtao.jin@hotmail.com

${ }^{\dagger}$ Yang Zhou and Ying Zhang contributed equally to this work

1 Department of Neurology and Neuroscience Center, The First Hospital of Jilin University, Xinmin Street 71\#, Changchun 130021, China

Full list of author information is available at the end of the article
}

as immature transitional B cells, where they eventually develop into mature B cells $[4,5]$. However, in humans, the maturation of $\operatorname{TrB}$ cells may not be restricted to the spleen [5]. TrB cells account for approximately $4 \%$ of all $\mathrm{CD} 19^{+} \mathrm{B}$ lymphocytes in healthy individuals [6]. They are present in human bone marrow [5, 7], peripheral blood [8], cord blood [5, 6], and secondary lymphoid tissues (i.e., spleen [5, 9], tonsils [10], lymph nodes [5], and gutassociated lymphoid tissue [GALT]) [3], whereas mouse TrB cells are found only in the bone marrow, blood, and spleen, and not in the lymph nodes $[4,5]$. CD $24^{\text {hi }} \mathrm{CD} 38^{\mathrm{hi}}$ TrB cells are closely related to IL-10-producing regulatory B cells (Bregs) in terms of phenotypical and functional similarities [1]. TrB cells can also produce IL-10 and regulate $\mathrm{CD} 4^{+} \mathrm{T}$ cell proliferation and differentiation toward $\mathrm{T}$ helper (Th) effector cells [8]. The frequency of $\mathrm{CD} 24^{\text {hi }} \mathrm{CD} 38^{\text {hi }} \mathrm{TrB}$ cells is elevated in those with systemic lupus erythematosus (SLE) [8, 11, 12], Sjögren's syndrome (SS) [12], systemic sclerosis (SSc) [13], and

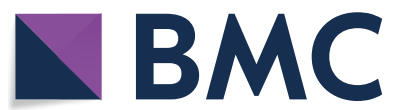

(c) The Author(s) 2020. This article is licensed under a Creative Commons Attribution 4.0 International License, which permits use, sharing, adaptation, distribution and reproduction in any medium or format, as long as you give appropriate credit to the original author(s) and the source, provide a link to the Creative Commons licence, and indicate if changes were made. The images or other third party material in this article are included in the article's Creative Commons licence, unless indicated otherwise in a credit line to the material. If material is not included in the article's Creative Commons licence and your intended use is not permitted by statutory regulation or exceeds the permitted use, you will need to obtain permission directly from the copyright holder. To view a copy of this licence, visit http://creativeco mmons.org/licenses/by/4.0/. The Creative Commons Public Domain Dedication waiver (http://creativecommons.org/publicdomain/ zero/1.0/) applies to the data made available in this article, unless otherwise stated in a credit line to the data. 
juvenile dermatomyositis [14]. However, a low frequency of $\mathrm{TrB}$ cells has been noted in those with neuroimmunological diseases, including multiple sclerosis (MS) [15] and neuromyelitis optica spectrum disorders (NMOSDs) [16]. Accumulating evidence has suggested $\operatorname{TrB}$ cells to be part of the integrated immune system, in fact, these cells have been found to be involved in the pathogenesis caused by human immunodeficiency virus, type 1 [17] and hepatitis $C$ virus infections [18], and T. brucei infections [19]. In addition, deletion of $\operatorname{Tr} B$ cells resulted in a lack of mature B cell compartments during T. brucei infection, thus preventing the host's ability of sustaining antibody responses against recurring parasitemic waves [19]. Since they are associated with several inflammatory diseases and are also found in circulation as well as tissues of healthy individuals, TrB cells are thought to perform distinct functions in immune-defense mechanisms.

Our understanding of $\operatorname{TrB}$ cells in healthy individuals as well as in those with diseases still remains incomplete. This may partially be due to their low frequency in circulation, in case of both mice and humans. In this review, we describe the origin, development, function, and associated molecules of $\operatorname{TrB}$ cells in the context of autoimmune diseases, with an emphasis on their neuroimmunological implications.

\section{The origin and development of transitional B cells Transitional B cells in mice}

Mouse B lymphocytes originate from hematopoietic stem cells (HSCs) in the bone marrow and fetal liver after birth, where they subsequently mature via immunoglobulin heavy chain and light chain recombination [20-22]. Based on cell surface phenotype and expression of B-lineage genes and of heavy chain and light chain, $B$ cells in the bone marrow mainly include pre- $\mathrm{B}$, pro- $\mathrm{B}$, immature and recirculating $B$ lymphocytes [23]. Of the 20 million $\mathrm{IgM}^{+}\left(\mathrm{B}\right.$-cell receptor $\left.[\mathrm{BCR}]^{+}\right) \mathrm{B}$ cells generated in the mouse bone marrow every day, approximately $10 \%$ enter circulation, and 1-3\% reach the mature B cell pool [4]. The immature $B$ cells transit to the marginal sinuses and red pulp of the spleen through the bone marrow sinusoids and bloodstream, after which the immature transitional 1 (T1) B cells migrate into the periarteriolar lymphoid sheath (PALS) of the white pulp in response to positive selection [24, 25]. BCR-mediated negative selection occurs at the T1 B cell stage, which serves to remove the self-reactive $\mathrm{B}$ cells; the remaining $\mathrm{T} 1 \mathrm{~B}$ cells give rise to the late transitional B cells (T2/T3 B cells) $[26,27]$. These gradually develop into naïve follicular mature (FM) or marginal zone (MZ) B cells and eventually into mature naïve B cells (Fig. 1) [28, 29].

Recent data have suggested $\operatorname{TrB}$ cell development to be modulated by various factors. First, it may be influenced by the integrity of $B C R$ signaling $[4,9,30,31]$. The BCR is composed of an Ig- $\alpha / \operatorname{Ig}-\beta$ (CD79a/CD79b) heterodimer and a membrane-bound Ig molecule, which serves as a signal-transduction unit, linking the BCR with a complex of cytoplasmic signaling molecules $[4,9,32]$. For instance, mice lacking the cytoplasmic tail of Ig- $\alpha$ component of the BCR [4] or protein tyrosine kinase Syk [31] have shown restricted progression from $\mathrm{T} 1$ to T2 B cell subpopulations. $\mathrm{CD} 45^{-}$or Bruton's tyrosine kinase $(\mathrm{Btk})^{-}$mutant $\mathrm{CBA} / \mathrm{N}$ mice have shown arrested progression from $\mathrm{T} 2 \mathrm{~B}$ cells into mature $\mathrm{B}$ cells in the spleen $[9,30]$. Factors influencing the BCR signaling pathways may also limit various phases of $\operatorname{TrB}$ cell development [33-35]. For example, in signal-peptide-peptidase-like 2a (SPPL2a) $)^{-1-}$ mice, BCR signaling is impaired (to a great extent) by the accumulation of CD74 $\mathrm{N}$-terminal fragment, which blocks $\mathrm{B}$ cell development at the $\mathrm{T} 1$ stage [33]. B cell development in B cell activating factor receptor (BAFF-R, BR3) ${ }^{-1-}$ mice was blocked progressing from $\mathrm{T} 1$ stage to $\mathrm{T} 2$ stage $[34,35]$. The role of BAFF$\mathrm{R}$ signaling in $\operatorname{TrB}$ cell generation is secondary to that of BCR signaling [36].

Second, negative and positive selection is important for the survival of both immature and mature B cells [37]. $\operatorname{TrB}$ cells, especially those in the $\mathrm{T} 1$ cell subset, are the targets of the negative selection in normal mice [23,38]. Negative and positive selection of developing B cells promote a non-pathogenic B cell repertoire [21]. Negative selection occurs in $\mathrm{BCR}^{+}$immature $\mathrm{B}$ cells through $\mathrm{BCR}$ mediated apoptosis (central deletion), anergy, or receptor editing (secondary gene rearrangement), which removes self-reactive B cells $[28,39]$. Although TrB cells are limited in terms of receptor editing, they maintain their capacity for negative and positive selection [39]. Data from some previous studies had suggested BCR signaling to regulate antigen-dependent positive selection of $\operatorname{Tr} B$ cells $[40,41]$, thereby enhancing survival and/or clonal expansion [42, 43]. Kolhatkar et al. had demonstrated the positive selection of $\operatorname{TrB}$ cells expressing low-affinity selfreactive BCRs to be enhanced via the altered $B C R$ and Toll-like receptor (TLR) signaling [44].

Finally, the splenic microenvironment is required for the B cell development; it affects the $\operatorname{TrB}$ cell compartment $[9,43]$. Although mature B cells establish connections between lymphoid tissues and blood, T2 cells are restricted to the splenic follicles [9]. Thus, TrB cells develop into follicular or MZ B cells in different splenic compartments [45].

\section{Transitional B cells in humans}

The process of B cell development in humans is similar to that in mice (Fig. 1); B cells originating from HSCs can be processed in the bone marrow, where they undergo 


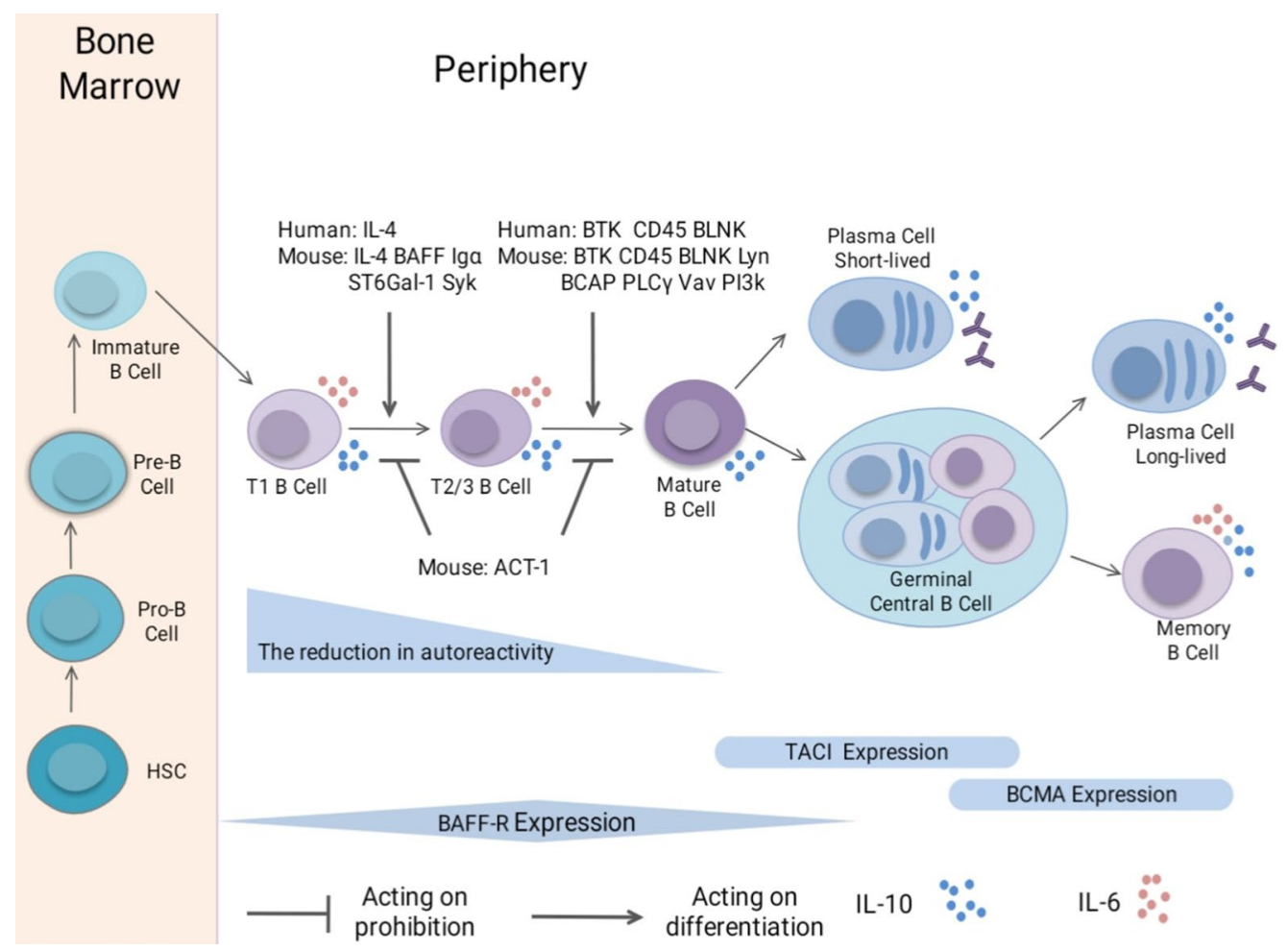

Fig. 1 B cell differentiation pathways and expression of TrB-associated molecules. In the bone marrow (BM), HSCs undergo several stages of differentiation before they develop into immature B cells, including the pro-B and pre-B cell stages. The immature B cells emigrate from the BM, subsequently differentiating into T1 B cells in the periphery and then to the late $\operatorname{TrB}(\mathrm{T} 2 / 3 \mathrm{~B})$ cells. This maturation step from T1 B cells to T2/3B cells requires IL-4, BAFF, Iga, ST6Gal-1, and Syk in mice and IL-4 in humans. The subsequent process of TrB cell differentiation into mature B cells requires BTK, CD45, and BLNK both in mice and humans, and Lyn, BCAP, PLCY, Vav, and PI3K in mice. ACT-1 in mice plays a negative role in the development of TrB cells. Autoreactivity gradually reduces during B cell maturation, especially during TrB cell development. The late TrB cells develop into mature $B$ cells, and give rise to either short-lived plasma cells or germinal center B cells. In the germinal center, they can undergo selection to differentiate into long-lived plasmablasts or memory B cells. B cells express three forms of BAFF receptors. BAFF-R is expressed on B cells from the TrB cell stage to the memory $B$ cell stage in $B$ cells, except in BM plasma cells, TACl is mainly expressed on memory $B$ cells and some active mature $B$ cells, whereas BCMA is expressed on memory B cells and plasma cells. IL-10 can be produced by TrB cells, mature B cells, plasmablasts, and memory B cells. IL-6 is expressed in TrB cells and memory B cells

heavy and light chain rearrangements before entering the peripheral compartment [1]. HSCs initially stem from common lymphoid progenitors and then develop into pro- $\mathrm{B}$ cells via rearrangement of the $\mathrm{D}$ and $\mathrm{J}$ segments following juxtaposition of a variable $\left(\mathrm{V}_{\mathrm{H}}\right)$ gene with the $\mathrm{DJ}_{\mathrm{H}}$ element $[46,47]$. Pro-B cells mature into pre- $B$ cells via the rearrangement of $\mu-\mathrm{H}$-chain gene segments, which couple with a surrogate light chain $[6,46$, 47]. After initial rearrangement of the light chain $(\mathrm{V}-\mathrm{L})$, human pre-B cells undergo 1 or 2 cell divisions and develop into immature B cells, which first express $\mu / \kappa$ or $\kappa / \lambda$ surface IgM receptors $[6,10,46,47]$. These immature $\mathrm{T} 1 \mathrm{~B}$ cells are thought to emigrate from the bone marrow, subsequently differentiating into $\mathrm{T} 2 \mathrm{~B}$ cells in the periphery, eventually giving rise to T3 B cells [48]. However, there is some disagreement regarding this process. TrB cells might be capable of departing from the bone marrow at either the $\mathrm{T} 1$ or $\mathrm{T} 2 \mathrm{~B}$ cell stage, and some $\mathrm{T} 1 \mathrm{~B}$ cells can differentiate into T2 B cells in the bone marrow, considering that similar proportions of $\mathrm{T} 1$ and $\mathrm{T} 2 \mathrm{~B}$ cell subsets has been noted in normal human bone marrow [7]. In agreement with previous findings in mice, positive and negative selection may also regulate the development of human $\operatorname{TrB}$ cells [47]. In normal human peripheral blood, approximately $40 \%$ of $\operatorname{TrB}$ cells show autoreactive behavior; the frequency is reduced to $20 \%$ when they are differentiated into mature naïve B cells $[47,49]$. TrB cell maturation requires Btk, demonstrating a possibility of $B C R$ engagement, and is accompanied by improved survival [48]. BAFF promotes immature B cell selection and non-autoreactive immature $B$ cells differentiation into $\operatorname{TrB}$ cells, although the role of BAFF in human TrB cell development has been controversial [36]. Some previous data had shown BAFF to have no effect on human $\operatorname{TrB}$ 
cells, although it serves as an efficient pro-survival factor for mouse TrB cells $[5,47,48]$. Some data has indicated that human $\mathrm{T} 1 \mathrm{~B}$ cell proliferation to be clearly induced by BAFF, though to a lesser extent than that of human T2 $\mathrm{B}$ cells [50]. Therefore, during the process of $\mathrm{TrB}$ cell differentiation into mature naïve $B$ cells, selection against self-reactive antibodies occurs and immune competence is gradually acquired in humans $[49,50]$.

Human $\operatorname{TrB}$ cells were first described in detail in 2005, and are often characterized by a $\mathrm{CD} 24^{\mathrm{hi}} \mathrm{CD} 38^{\mathrm{hi}}$ phenotype $[1,5]$. Human $\mathrm{CD} 24^{\mathrm{hi}} \mathrm{CD} 38^{\mathrm{hi}} \mathrm{TrB}$ cells represent approximately $4 \%$ of all $\mathrm{CD} 19^{+} \mathrm{B}$ cells in the peripheral blood, and constitute nearly $50 \%$ of B cells in cord blood and their proportion gradually declining during infancy [6]. The percentage of $\operatorname{TrB}$ cells in various normal mice tissues is different, and shown in Table 1 [4]. However, mouse $\operatorname{TrB}$ cells are not found in the lymph nodes owing to the absence of L-selectin expression in them [4]. In contrast, human $\operatorname{TrB}$ cells have been found in GALT, and previous data had indicated the T2 subset to be consistently enriched in GALT compared to the T1 subset [3]. Moreover, most T2 B cells isolated from human GALT were activated in response to intestinal bacteria, both in vitro and in vivo [3]. Therefore, the proportion of human $\mathrm{CD} 24^{\mathrm{hi}} \mathrm{CD} 38^{\mathrm{hi}} \mathrm{TrB}$ cells may also differ within various tissues.

We along with other investigators had previously shown that Bregs contribute to the maintenance of immune tolerance and modulation of immune responses $[1,51-53]$. Currently, human Bregs have been noted at different stages of $B$ cell development and consist of various $B$ cell subsets, namely $C D 24^{\text {hi }} C D 38^{\text {hi }}$ immature $\operatorname{TrB}$ cells [11], CD24 ${ }^{\mathrm{hi}} \mathrm{CD} 38^{\mathrm{lo}} \mathrm{CD} 27^{+}$memory B cells [54], and
CD24 ${ }^{-} \mathrm{CD} 38^{+} \mathrm{CD} 27^{\text {int }}$ IL-10-secreting plasmablasts [55]. Human IL-10-producing Bregs are enriched within the $\mathrm{CD} 24^{\text {hi }} \mathrm{CD} 38^{\text {hi }}$ immature $\operatorname{TrB}$ cell subset $[1,11]$. These observations reveal a relationship between human $\operatorname{TrB}$ cells and Bregs. Taken together, a detailed understanding of $\operatorname{TrB}$ cell development and characterization would be beneficial for understanding mechanisms in autoimmunity and providing new ideas for potential treatment strategies.

\section{Phenotypes and functional properties of TrB cells}

TrB cells can be separated into two or more distinct subsets, both in mice and humans (Table 1), based on their surface phenotypes and functional features [28]. Loder and colleagues had proposed two subtypes of mouse $\operatorname{TrB}$ cells, namely transitional 1 (T1) and transitional 2 (T2) $B$ cells, depending on the expression status of CD21 and IgD [4]. Allman et al. had divided TrB cells into three subsets (T1 B cells, T2 B cells, and T3 B cells) based on the expression of AA4 (CD93), CD23, and sIgM [30]. Disagreement exists regarding the classification of human TrB cells. For instance, Sims et al. had separated them into $\mathrm{T} 1$ and $\mathrm{T} 2$ subpopulations, based on the expression level of IgD and CD38 and the minimal gradation of other surface markers such as CD24 [5]. Subsequently, human $\operatorname{TrB}$ cells were discriminated into three subsets, including T1 B cells, T2 B cells, and T3 B cells [50]. In 2016, Simon first proposed human $\mathrm{CD} 24^{\mathrm{hi}} \mathrm{CD} 38^{\mathrm{hi}} \mathrm{TrB}$ cells to not contain only one subset, but rather 4 subsets based on CD27, IgM, IgD, CD10, CD21, and CD32 expression. T1-T3 B cells express low levels of CD27, whereas CD27 ${ }^{+}$ TrB cells express CD27, CD24, and CD38 at high levels. In T1 B cells, the expression of IgM, CD10, and CD32 is

Table 1 Differences of phenotypes, locations, proportion of B cells, and subset ratios between mouse and human transitional B cells

\begin{tabular}{|c|c|c|}
\hline & Mouse TrB cell & Human TrB cell \\
\hline \multirow[t]{3}{*}{ Phenotypes } & 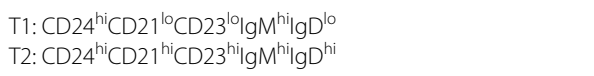 & 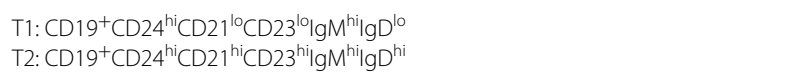 \\
\hline & \multirow[t]{2}{*}{ 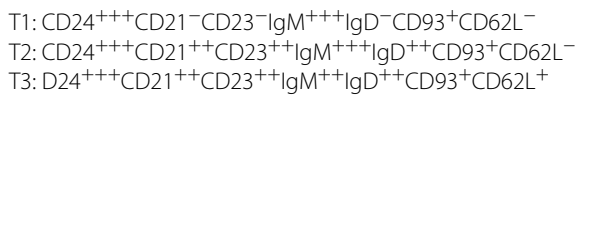 } & 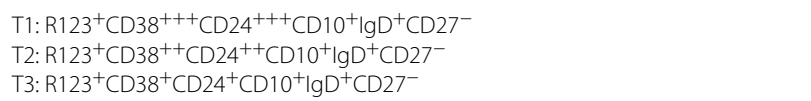 \\
\hline & & 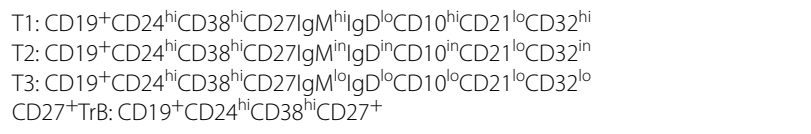 \\
\hline Locations & BM, PB, Spleen & $\mathrm{BM}, \mathrm{PB}, \mathrm{CB}$ and secondary lymphoid tissues (spleen, tonsil, lymph node and GALT) \\
\hline \multirow{3}{*}{$\begin{array}{l}\text { The proportion } \\
\text { of B cells }\end{array}$} & BM: $15-20 \%$ & BM: $6.3 \%$ \\
\hline & PB: $15-20 \%$ & PB: $4 \%$ \\
\hline & Spleen: 10-15\% & CB: $50 \%$ \\
\hline \multirow{3}{*}{$\begin{array}{l}\text { Subset ratios } \\
\text { (TrB: FM B) }\end{array}$} & BM 1:0.6 & BM 1:2.1 \\
\hline & PB 1:0.4 & PB 1:2.2 \\
\hline & Spleen 1:3.7 & Spleen 1:21.9 \\
\hline
\end{tabular}


high while that of IgD and CD21 is low. T2 B cells show moderate IgM, IgD, CD10, and CD32 expression and low CD21 expression. However, T3 B cells express IgM, IgD, CD10, CD21, and CD32 at low levels [8]. Notably, some studies indicated that $\mathrm{CD} 27^{+} \mathrm{TrB}$ cells serve as a type of Bregs and may not just being the transitional B cells [50, 56].

In mice, T1 B cells clearly stop proliferating, and undergo apoptosis in response to BCR cross-linking, although discrepant findings have been reported for T2 B cells [28]. Some data have shown T2 B cells to proliferate and get induced to differentiate into follicular mature B cells in response to BCR engagement [4, 23 ], whereas other findings have suggested T2 B cells to not proliferate in response to the same signals [30, 57]. Mouse $\operatorname{Tr} B$ cells are unable to proliferate following sIgM cross-linking in vitro [30]. However human $\operatorname{TrB}$ cells produce low amounts of Ig and exhibit less differentiation, proliferation, and chemotaxis in vitro than mature B cells [58]. Mouse splenic IL-10-producing Bregs include $\mathrm{CD} 2 \mathrm{1}^{\mathrm{hi}} \mathrm{CD} 23^{\mathrm{hi}} \mathrm{IgM}^{\mathrm{hi}}$ transitional 2-MZ precursor (T2-MZP) B cells [59] and $\mathrm{CD} 1 \mathrm{~d}^{\text {hi }} \mathrm{CD} 5^{+} \mathrm{B}$ cells [60]. T2-MZP B cells can suppress IFN- $\gamma$ production by releasing IL-10 [59]. In addition, T2-MZP B cells also significantly reduce the proportion of $\mathrm{CD} 4^{+} \mathrm{IFN}-\gamma^{+}$ and $\mathrm{IL}-17^{+} \mathrm{T}$ cells, and contribute to differentiation into $\mathrm{CD} 4^{+} \mathrm{Foxp}^{+} \mathrm{T}$ cells when cultured with effector $\mathrm{CD} 4^{+} \mathrm{CD} 25^{-} \mathrm{T}$ cells $[61,62]$. Similar to the observations in mice, human $\mathrm{IL}-10^{+} \mathrm{B}$ cells with a transitional $\mathrm{CD} 19^{+} \mathrm{CD} 24^{\text {hi }} \mathrm{CD} 38^{\mathrm{hi}}$ phenotype have been found in peripheral blood of healthy individuals [11]. The main functions of human $\mathrm{CD} 19^{+} \mathrm{CD} 24^{\mathrm{hi}} \mathrm{CD} 38^{\mathrm{hi}} \mathrm{TrB}$ cells discovered at this time have been summarized in Fig. 2 . First, IL-10 produced by $\operatorname{TrB}$ cells suppresses autoreactive $\mathrm{CD}^{+} \mathrm{T}$ cell proliferation $[1,11,63]$. Second, $\operatorname{TrB}$ cells suppress the production of pro-inflammatory cytokines by limiting the expansion of $\mathrm{CD}^{+}{ }^{+}$Th1 cells (IFN- $\gamma$ and TNF- $\alpha$ production) and CD4 ${ }^{+}$Th 17 cells (IL-17 production), which is dependent on IL-10, programmed cell death-ligand 1 (PD-L1), CD80, and CD86, but not on transforming growth factor- $\beta$ (TGF- $\beta$ ) $[1,11,56]$. Third, $\mathrm{TrB}$ cells prevent the $\mathrm{CD} 4^{+} \mathrm{T}$ cells from differentiating into Th1 and Th17 cells and promote the conversion of effector $\mathrm{CD}^{+}{ }^{+} \mathrm{T}$ cells into $\mathrm{CD}^{+}{ }^{+} \mathrm{FoxP}^{+}$Tregs while

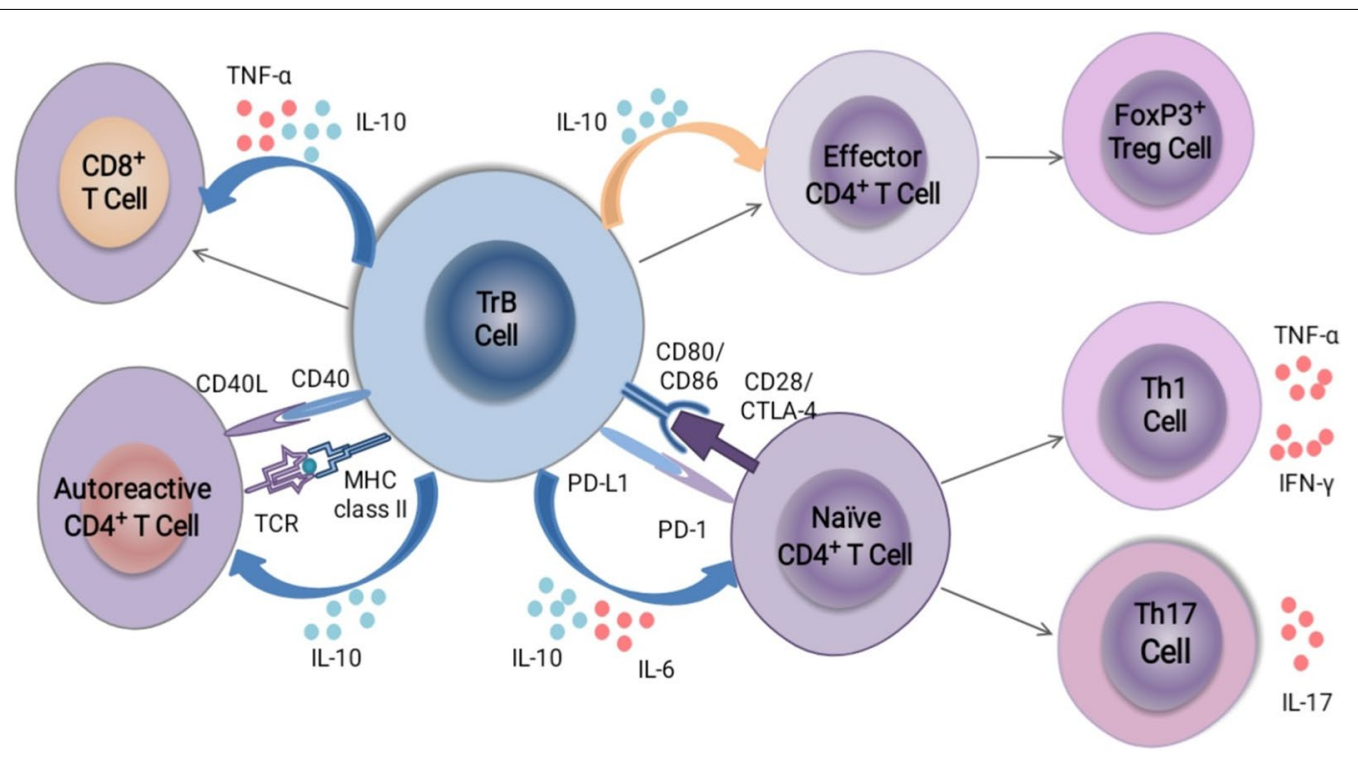

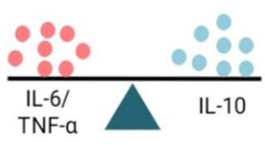

Functional Stability
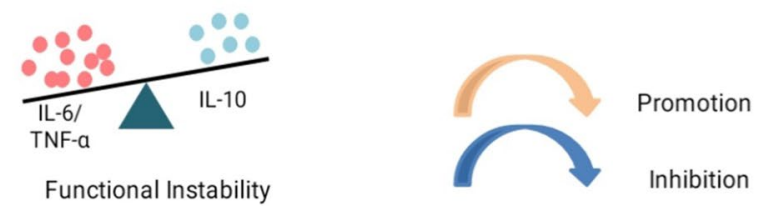

Fig. 2 The main functions of transitional B cells. 1) TrB cells suppress the proliferation of autoreactive CD4 ${ }^{+} \mathrm{T}$ cells. 2) TrB cells prevent the differentiation of $\mathrm{CD}^{+}{ }^{+} \mathrm{T}$ cells into Th1 and Th17 cells, thus limiting the production of excessive pro-inflammatory cytokines (TNF-a, IFN- $\gamma$, and IL-17). 3) TrB cells promote the conversion of effector CD4 ${ }^{+}$T cells into CD4 ${ }^{+}$FoxP3 ${ }^{+}$Tregs. 4) TrB cells inhibit CD8 ${ }^{+} \mathrm{T}$ cell responses. The suppressive functions of TrB cells are partially dependent on the secretion of IL-10, which can down-regulate CD86 expression in an autocrine manner. TrB cells can also secrete pro-inflammatory cytokines, such as IL-6 and TNF-a. The imbalance between pro- and anti-inflammatory cytokine productions in TrB cells may affect their functional stability and thus participate in the development of immune diseases 
limiting the production of excessive pro-inflammatory cytokines $[11,64]$. Finally, $\operatorname{TrB}$ cells inhibit $\mathrm{CD}^{+} \mathrm{T}$ cell responses and maintain invariant nature killer $\mathrm{T}$ (iNKT) cells $[1,65,66]$. Recent findings have revealed different subpopulations of $\operatorname{TrB}$ cells to have different functions. For example, T2/T3 B cells have a significant capacity to decrease $\mathrm{CD} 4^{+} \mathrm{T}$ cell proliferation (contrary to other subpopulations), and only $\mathrm{CD} 27^{+} \operatorname{TrB}$ cells significantly reduced TNF- $\alpha$ and IFN- $\gamma$ production by $\mathrm{CD} 4^{+} \mathrm{T}$ cells [8]. In addition to producing anti-inflammatory factors, $\operatorname{TrB}$ cells can also secrete pro-inflammatory cytokines such as IL-6 and TNF- $\alpha[13,14,56,67,68]$. Data from previous studies had shown the frequency of IL-6-producing TrB cells to be elevated in SLE, SS, and other immune diseases [13, 14, 68]. IL-6 restricts the differentiation of $\mathrm{CD} 4^{+} \mathrm{T}$ cells into Tregs and induces autoreactive Th1/Th17 T-cell responses $[69,70]$. Therefore, the pro- and anti-inflammatory cytokines produced in $\operatorname{TrB}$ cells may affect their functional stability $[13,67]$.

In summary, $\operatorname{TrB}$ cells comprise different subsets, showing unique phenotypic and regulatory functional profiles. The frequencies and functions of $\operatorname{Tr} B$ cells may be altered in different autoimmune diseases.

\section{The development and function of TrB-associated molecules}

\section{BAFF: $B$ cell activating factor}

BAFF (also known as BLys, TNFSF13B, TALL1, and ZTNF4) is a member of the TNF family that can be induced by various inflammatory cytokines, particularly IFN- $\gamma$ [71-73]. It is mainly produced by some lymphocytes (activated B cells and T cells), innate immune cells (neutrophils, macrophages, monocytes, dendritic cells, and follicular dendritic cells), and non-lymphoid cells (astrocytes, synoviocytes, epithelial cells, and cytotrophoblasts) [71]. BAFF promotes B cell maturation and regulates immune responses via three receptors: transmembrane activator and CAML interactor (TACI, also known as TNFRSF13B and CD267), BAFF receptor (BAFF-R, also known as BR3, TNFRSF13C, and CD268) and $\mathrm{B}$ cell maturation antigen (BCMA, also known as TNFRSF17 and CD269) [71, 74]. In humans, TACI is mainly expressed in memory $B$ cells and in some active mature B cells, whereas BCMA is presented in memory $B$ cells and tonsillar, splenic, and bone marrow plasma cells (Fig. 1) [71, 74]. BAFF-R is expressed from TrB cell stage to memory $B$ cell stage, in absence of bone marrow plasma cells, where it is expressed at higher levels in T2 B cells than in T1 B cells or mature B cells (Fig. 1) [71, 74].

Recently, many studies have been shown the role of BAFF in mice $\operatorname{TrB}$ cell development. Such as, gene-knockout studies have demonstrated the differentiation of $\mathrm{T} 1 \mathrm{~B}$ cells into $\mathrm{T} 2 \mathrm{~B}$ cells in $\mathrm{BAFF}^{-/-}$or
BAFF- $\mathrm{R}^{-1-}$ mice to be mostly blocked, resulting in fewer T2/3 and mature B cells [34, 46, 74]. Recent data have also suggested BAFF to promote the differentiation of T1 $B$ cells into T2 B cells, and BAFF-R to be necessary for survival during the transition from $\mathrm{T} 2 \mathrm{~B}$ cells to $\mathrm{MZ} \mathrm{B}$ cells in mice $[34,75]$. Clearly, BAFF binding to BAFF-R promotes the survival of T2, T3, and mature B cells [34, 75]. In vitro and in vivo data have shown BAFF and tonic $\mathrm{BCR}$ signaling to cooperate to contribute the differentiation of $\mathrm{CD} 23^{-} \operatorname{TrB}$ into $\mathrm{CD} 23^{+} \operatorname{TrB}$ cells [36]. Additionally, a synergy between optimal BAFF-R signaling and tonic BCR signals can contribute to positive selection and differentiation of non-autoreactive immature B cells into $\operatorname{TrB}$ cells [36]. BAFF- $\mathrm{R}$ expression levels are regulated by BCR signaling in $\operatorname{TrB}$ cell subtypes [37]. But, some observations in humans have been shown differences or inconsistencies compared with mice studies. Furthermore, the role of BAFF in human TrB cell development has been controversial, but BAFF promotes immature B cell selection and non-autoreactive immature $B$ cells differentiation into $\operatorname{TrB}$ cells in humans [36]. Some previous data had shown BAFF to have no effect on human $\operatorname{TrB}$ cells [5, $47,48]$, while some data has indicated that human T1 B cell proliferation to be clearly induced by BAFF, though to a lesser extent than that of human T2 B cells [50]. BAFF, which is necessary for B cell survival and maturation, suppressed IFN- $\gamma$ production in vitro and inhibited the proliferation of anti-CD3-stimulated $\mathrm{CD} 4{ }^{+} \mathrm{CD} 25^{-}$ $\mathrm{T}$ cells by inducing Bregs [2]. BAFF overexpression in serum promoted the malignant proliferation of B cells, leading to autoimmune diseases [34].

\section{IL-10}

IL-10 is a broad-spectrum immunomodulatory cytokine that modulates antigen presentation of cells, inhibits $\mathrm{T}$ cell proliferation, and maintains Treg functions [76]. IL-10 is produced by most types of hematopoietic cells in mice, and almost all types of B cells in humans [2, 8]. IL-10-producing $B$ cells were shown to be available in the $\operatorname{TrB}$ cell compartment [1]. In other words, $\operatorname{TrB}$ cells seem to exert their immunosuppressive effects mainly by producing IL-10. For example, IL-10 produced by $\mathrm{CD} 19^{+} \mathrm{CD} 24^{\mathrm{hi}} \mathrm{CD} 38^{\text {hi }} \mathrm{TrB}$ cells down-regulate CD86 in an autocrine manner, eventually suppressing $\mathrm{CD} 4^{+} \mathrm{T}$ cells proliferation and reducing IFN- $\gamma$ and TNF- $\alpha$ production [63, 64]. In addition, human $\operatorname{TrB}$ cells produce more IL-10 after CD40 engagement, demonstrating IL-10 as an essential factor for various co-stimulatory molecules $[64,76]$. Taken together, the findings indicate IL-10 to exert important immune regulatory functions in TrB cells. 
IL-4

IL-4 is a multifunctional cytokine that promotes mature $B$ cell activation and induces $B$ cell differentiation, proliferation, and antibody secretion by acting as a cofactor for lipopolysaccharides, CD40L, and antigen stimulation [77, 78]. IL-4 stimulates the development of CD23- ${ }^{-}$TrB cells into $\mathrm{CD} 23^{+} \mathrm{TrB}$ cells, an effect comparable to that driven by BAFF [77]. However, IL-4 was found to render bone marrow TrB cells refractory to anti-IgM apoptotic signals, which was distinct from BAFF [77]. Thus, IL-4 and stromal cells play major roles in improving the survival of human T1 B cells and promoting their maturation [5]. Taken together, the findings revealed IL- 4 to contribute to $\operatorname{TrB}$ cell differentiation and maturation both in mice and humans.

\section{IL-6}

IL-6 is a multi-functional cytokine involved in the pathogenesis of autoimmune diseases [79]. It is produced by various types of immune and stromal cells [79, 80]. Some studies have shown that IL-6 may promote the differentiation of naive $\mathrm{CD} 4^{+} \mathrm{T}$ cells into Th17 cells in both mice and humans [81, 82]. IL-6 blockade was used in experimental autoimmune encephalomyelitis (EAE), an animal model of MS. It was found that it can suppress Th1 and Th17 cellular responses, leading to reduced $\mathrm{T}$ cells infiltration into the central nervous system (CNS) during EAE period [83]. IL-6 is also produced by $\operatorname{TrB}$ cell and the frequency of IL-6-producing TrB cells was seen to be elevated in patients with SLE, SS and other immune diseases $[13,14,68]$.

\section{CD40}

CD40 is a co-stimulatory member of the tumor necrosis factor receptor (TNFR) super family and is expressed in both immune and non-immune cells [84]. CD40L (CD154) is the major ligand of CD40, and is predominantly expressed in activated CD4 ${ }^{+}$T cells; CD40-CD40L interactions can inhibit $\mathrm{T}$ cell proliferation and differentiation into Th1 cells $[84,85]$. Some studies have shown that human TrB cells produce more IL-10 and express higher levels of the IL-10 receptor after CD40 engagement when compared with other B cell subsets, leading to a decreased expression of CD86 in TrB cells and proliferation of CD4 ${ }^{+} \mathrm{T}$ cells $[11,63,85]$. However, CD40Lblocking antibodies were used when co-cultured healthy TrB cells with $\mathrm{CD} 4{ }^{+} \mathrm{CD} 25^{-}$effector T cells, which were unable to affect the production of IFN- $\gamma$ or TNF- $\alpha[11$, 85]. In a mouse model of EAE, $\mathrm{B}$ cells from $\mathrm{CD}_{40}{ }^{-1-}$ mice failed to produce IL-10 or induce disease remission [86]. In summary, CD40-CD40L signaling plays a critical role in maintaining appropriate immune responses in both mice and human.
ACT-1

ACT-1 (Traf3ip, Ciks) contains a helix-loop-helix motif at its $\mathrm{N}$ terminus and a coiled-coil at the $\mathrm{C}$ terminus, and it plays a negative role in autoimmunity through its differential impacts on both CD40-CD40L and BAFF-mediated pathways $[87,88]$. CD40 and BAFF signaling appear to be necessary for B cell survival and maturation, especially in the transitional stages $[34,86]$. In ACT-1 deficient mice, the number of T1 and T2 B cells in the spleen is significantly expanded; BAFF stimulation induces more $\mathrm{T} 1$ cell survival and efficiently promotes $\mathrm{T} 1$ cell maturation into $\mathrm{T} 2$ cell in vitro $[88,89]$. During transitional stages, ACT-1 potentially promotes the elimination of autoreactive B cells and regulation of peripheral B cell homeostasis [89]. Together, the findings support the view that the adaptor molecule ACT-1 is a key regulator of $\operatorname{TrB}$ cells.

\section{ST6GaL-1: ST6Beta-galactosamide alpha-2,3-sialyltransferase 1}

ST6GaL-1 is a sialyltransferase, and its cognate $\alpha-2,6-$ sialyl catalytic product can interact with CD22 (B cell complex accessory molecule) [90]. ST6Gal-1 is widely distributed in many tissues with high levels being noted in B cells, liver, and lactating mammary glands [91, 92]. Extrinsic sialylation by ST6GaL-1 contributes to the development of TrB cells, BAFF and BCR-mediated signaling [93]. Co-culturing immature B cells with ST6Gal-1 resulted in an increased number of TrB cells, demonstrating circulating ST6GaL-1 as a pro-survival factor important for BAFF utilization by non-autoreactive $\operatorname{TrB}$ cells [93]. Some studies have shown CD22 to recognize the a2,6-sialic acid produced by ST6Gal-1, indicating that the humoral immunodeficiency may exist in ST6GaL-1 ${ }^{-1-}$ animals [94, 95].

\section{Transitional B cells in autoimmune rheumatic diseases and neuroimmune disorders TrB cells and TrB-associated molecules in autoimmune rheumatic diseases}

At present, most studies on TrB cells and TrB-associated molecules in non-neuroimmune disorders are related to autoimmune rheumatic diseases (AIRDs); however, the etiology of most AIRDs still remains poorly understood. AIRDs are known to produce pathogenic antibodies and cause damage to different target organs and tissues [64, $68,84,96,97]$. For example, SLE can affect most organs in humans, whereas SS mainly affects the exocrine glands (labial glands and lacrimal glands) and RA primarily involves the joints and surrounding tissues [64, 68, 84]. Related observations have revealed that B cell-targeting therapy can control the development of such diseases [68, 
98]. Therefore, B cells play important roles in the pathogenesis of AIRDs. The abundance of $\operatorname{TrB}$ cells and their impairment of immune-regulatory functions may vary in different diseases. The frequency of $\operatorname{TrB}$ cells is expanded in SLE [8, 11, 12], SS [12], and SSc [13], whereas it is decreased in RA before treatment [12, 64].

Like Bregs, TrB cells exert a protective role, both in healthy individuals and in those with AIRDs, partially via IL-10 production. However, isolated $\operatorname{TrB}$ cells in patients with SLE fail to inhibit IFN- $\gamma$ and TNF- $\alpha$ production by $\mathrm{CD}^{+} \mathrm{T}$ cells [11], while $\mathrm{TrB}$ cells in healthy individuals can maintain the balance between Th1/Th17 and Tregs populations [64]. Furthermore, $\operatorname{TrB}$ cells from active RA cases restrict $\mathrm{CD} 4^{+} \mathrm{T}$ cell differentiation into Tregs and Th17, while maintaining the ability to inhibit Th1 development [64]. Besides IL-10, other TrB cell-associated molecules also play roles in auto-immune diseases. More IL-6-producing $\operatorname{TrB}$ cells are found in those with SLE and SSc than in healthy controls, which are positively correlated with disease activity and serum anti-dsDNA autoantibody titers in SLE cases [13, 68]. IL-6 is a proinflammatory cytokine that suppresses the generation of Tregs and contributes to the production of $\mathrm{CD} 4^{+}$Th17 cells [69]. Therefore, $\operatorname{TrB}$ cells can produce both antiinflammatory and pro-inflammatory cytokines to exert their immunomodulatory functions. In some immune diseases, the frequency of $\operatorname{TrB}$ cells is augmented and positively correlated with the disease activity, although their immune-regulatory function is impaired [11, 13]. Mounting evidence has suggested interferon (IFN) signature, TLR9 response impairment, and CD19 down-regulation of $\operatorname{TrB}$ cells are involved in those with SLE, thereby interfering with the removal of autoreactive $B$ cells at the $\operatorname{TrB}$ cell stage, and leading to the production of pathogenic antibodies by the surviving autoreactive $B$ cells $[68,96]$. In addition, SLE plasma with IFN- $\alpha$ efficiently induces IL- 6 expression in $\operatorname{TrB}$ cells, indicating IFN- $\alpha$ to possibly play an important role in stimulating $\operatorname{TrB}$ cells to produce IL-6 [68].

Taken together, these findings indicate that the participation of $\operatorname{TrB}$ cells in pathogenesis of AIRDs, and reveal that impairment of their immune-regulatory functions may reflect their inability to prevent the processes underlying autoreactive responses and inflammation.

\section{TrB cells and TrB-associated molecules in MS and EAE}

MS is considered a chronic inflammatory demyelinating disease of the CNS, leading to the loss of myelin, along with axonal and neuronal degeneration [51, 99102]. The pathologic features of MS are typically characterized by the dissemination of time and space [101, 102]. Historically, the factors considered to induce MS include the activation of pathogenic Th1, Th17, and
$\mathrm{CD} 8^{+}$myelin auto-reactive $\mathrm{T}$ cells, in addition to genetics, and environmental factors, and infections [99, 100, 103]. In support of this animal model, EAE also can be induced by myelin-specific CD $4^{+} \mathrm{T}$ cells and $\mathrm{CD} 8^{+} \mathrm{T}$ cells [99]. Recently, therapies targeting $B$ cells and $B$ cell cytokines (rituximab, ocrelizumab, ofatumumab, and tabalumab) have been shown to suppress MS disease activity [101, 102]. Furthermore, B cell depletion in MS can reduce auto-antibodies and pro-inflammatory cytokines produced by $\mathrm{B}$ cells and impair antigen presentation [103, 104]. B cell infiltration was found in the brain tissues of patients with MS, and oligoclonal bands (clonal IgG) and antibody-secreting plasma cells have been discovered in the cerebrospinal fluid [99, 105]. Meningeal ectopic B cell follicles were formatted in secondary-progressive MS [101]. Collectively, these observations demonstrated the participation of $B$ cells in the pathogenesis of MS. Recent research has shown B cells to be virtually depleted after anti-CD20 treatment in EAE, then after 6-8 weeks, they gradually reappeared in the bone marrow, spleen, lymph nodes, and blood [106]. Surprisingly, splenic $\operatorname{Tr} B$ and follicular $\mathrm{B}$ cells were found to be almost absent in EAE treated with anti-CD20, at 8 weeks post-treatment [106].

In addition to their involvement in MS pathogenesis, B cells also exert immune-regulatory effects by producing anti-inflammatory cytokines directly or indirectly [102, 107]. Bregs play a regulatory role in MS by helping with the maintenance of immune tolerance $[1,108]$. In mice, IL-10-producing $\mathrm{CD} 1 \mathrm{~d}^{\text {hi }} \mathrm{CD} 5^{+} \mathrm{B}$ cells play a more substantial role in suppressing EAE initiation and development than other B cells $[60,109]$. TrB cells account for a considerable proportion of functional Breg cells $[1,11]$. Significantly fewer $\operatorname{TrB}$ cells were detected in those with MS/clinically isolated syndrome (CIS) than in healthy individuals, and the frequency of $\operatorname{TrB}$ cells was increased after related treatments (e.g., thymosin- $\alpha 1$, fingolimod) $[15,110,111]$. Similar to that of $\operatorname{TrB}$ cells, the frequency of other circulating B-cell subsets (naïve, MZ-like, and memory B cells) in peripheral blood of MS/CIS cases were comparable to those in healthy controls [15]. Some data further demonstrate TrB cells to be capable of homing to inflamed sites in the CNS through up-regulated expression of $\alpha 4$ and $\beta 1$ integrins during the early phase of MS [15]. TrB cells in the peripheral blood of those with MS who were treated with fingolimod, produced more IL-10 and less TNF- $\alpha$ than memory and mature naïve B cells, and expressed low levels of CD80 [111]. Related studies have shown the immune-regulatory role of Bregs to be partly mediated through the production of IL-10, IL-35, TGF- $\beta$ and PD-L1 $[63,64,103]$. In EAE, CD40 signaling is required for inducing IL-10 competence $[86,112]$. Subsequently, IL-21 drives the expansion 
of IL-10-producing B cell as well as generation of effector cells $[86,112]$. IL-6-producing B cells are involved in the pathogenesis of EAE/MS [70, 113]. Over $65 \%$ of IL-6 is primarily produced by $\mathrm{B}$ cells, which exacerbates EAE, augments the autoreactive $T$ cell responses of Th1 and Th17 types, and inhibits the generation of Tregs $[98,114]$.

$\operatorname{TrB}$ cells, like Bregs, play an immune-regulatory role in MS/EAE; however, further research would be required to show how $\operatorname{TrB}$ cells activate, proliferate, and function in MS. Many approved disease-modifying drugs for MS have been able to reduce the number of relapses and decrease activity of the disease; however, further research can focus on the understanding of pathogenic mechanisms underlying MS/EAE in order to explore the development of more specific and effective therapeutic approaches.

\section{TrB cells and TrB-associated molecules in neuromyelitis optica spectrum disorders}

NMOSDs are idiopathic inflammatory demyelinating diseases affecting the CNS, and are clinically characterized by longitudinally extensive transverse myelitis (LETM) and severe optic neuritis (ON), traditionally considered a variant of Asian MS [115-118]. Lennon et al. first discovered a serological marker of neuromyelitis optica (NMO), known as the aquaporin-4 antibody (AQP4-Ab) or NMO-IgG, making NMO independent of MS [119]. The identification of AQP4-Ab broadened the spectrum of NMO $[116,120]$. AQP4-Ab is involved in the pathogenesis of NMOSDs, depending on the presence of B cells, $T$ cells, and complement, suggesting NMOSDs to possibly be primarily mediated by humoral immunity $[117,121]$. NMOSDs cases can be associated with other autoimmune diseases such as SLE, SS, and thyroiditis, implying that NMOSDs may involve a mechanism resembling that of autoimmune diseases $[115,117]$. Like SLE and other autoantibody-mediated immune diseases, NMOSDs cases have deficiencies in the integrity of the central and peripheral B cell tolerance checkpoints [122]. In addition, impaired peripheral $B$ cell tolerance checkpoints interfere with the removal of autoreactive B cells, leading to increase the reservoir self-reactive new emigrant/ transitional and mature naive $B$ cells, and this process has relation with the production of pathogenic anti-AQP4 autoantibody [122].

Currently, only a few studies have been conducted to explore the roles of $\operatorname{TrB}$ cells and TrB-associated molecules in NMOSDs. Specifically, fewer $\mathrm{CD} 19^{+} \mathrm{CD} 24^{\mathrm{hi}} \mathrm{CD} 38^{\mathrm{hi}} \mathrm{TrB}$ cells were found in those with NMOSDs than in those with MS $[16,52]$. The frequencies of $\mathrm{CD} 19^{+} \mathrm{CD} 27^{+}$memory $\mathrm{B}$ cells and mature $\mathrm{B}$ cells are not significantly different between those with NMOSDs and $\mathrm{HC}$, whereas the percentage of $\mathrm{CD} 19^{+} \mathrm{CD} 5^{+} \mathrm{CD} 1 \mathrm{~d}^{\text {hi }}$
Bregs decreased in NMOSDs cases [16, 52]. The proportion of $\operatorname{TrB}$ cells has been demonstrated to be lower in AQP4-positive group than in AQP4-negative group [16, 52]. Moreover, the frequencies of IL-10-expressing $B$ cells among all lymphocytes are reported to be lower in those with NMOSDs than in those with MS and in healthy individuals [16]. This indirectly shows the impairment of immunomodulatory function of $\operatorname{TrB}$ cells in NMOSDs due to a reduction of $\operatorname{TrB}$ cells and/or IL-10; IL-10 production in $\operatorname{TrB}$ cells was not measured in most studies. Rituximab treatment in those with NMOSDs lowered the number of $\mathrm{CD} 27^{+}$memory $\mathrm{B}$ cells and increased the number of $\mathrm{CD} 24^{\text {hi }} \mathrm{CD} 38^{\text {hi }} \mathrm{TrB}$ cells [123]. Related studies also showed elevation of BAFF, IL-6, and IL-21, both in serum and CSF of NMOSDs cases, although expression of these molecules in $\operatorname{TrB}$ cells still remains unclear [117, $121,124]$. AQP4-Ab is mainly derived from a subtype of $B$ cells, CD27 ${ }^{\text {hi }} \mathrm{CD} 38^{\mathrm{hi}} \mathrm{CD} 180^{-} \mathrm{B}$ cells, survival of which depends on signaling via the IL-6 receptor, thus indicating IL-6-dependent B cells to possibly be associated with NMOSDs pathogenesis [117]. Korn and colleagues had provided evidence of IL-6 and IL-21 suppressing Tregs production, despite inducing IL-17 secretion from CD4 ${ }^{+}$ Th17 cells [69]. Further studies would be required to explore the mechanism driving the IL- 6 production of TrB cells in those with NMOSDs. If the proportion of IL6-producing $\operatorname{TrB}$ cells is elevated in NMOSDs cases, then IL-6 secretion may impair the immune-regulatory function of $\operatorname{TrB}$ cells.

In summary, $\operatorname{TrB}$ cells and $\operatorname{TrB}$-associated molecules are involved in the pathogenesis of NMOSDs. However, further research would be required for determining their immunomodulatory roles in NMOSDs cases and for clarifying whether they are involved in AQP4-Ab production. These considerations are important for understanding whether $\operatorname{TrB}$ cells and $\operatorname{TrB}$-associated molecules can serves as new therapeutic targets for those with NMOSDs.

\section{Conclusion and perspective}

Although recent studies have demonstrated regulatory roles of $\mathrm{TrB}$ cells, the same may vary across different autoimmune diseases due to the production of diverse levels of anti-/pro-inflammatory cytokines, or induction of $\mathrm{B}$ cell immune-tolerance defects, leading to increasing autoreactive B cells and pathogenic antibodies. Further studies focusing on the activation, proliferation, and exact functional mechanisms of $\operatorname{TrB}$ cells in healthy individuals and in those with various immune/inflammatory diseases would be necessary in the future. Success in such endeavors may help in clarifying the role of $\operatorname{TrB}$ cells as disease biomarkers and/or therapeutic targets. 


\begin{abstract}
Abbreviations
TrB cells: Transitional B cells; IFN- - : Interferon-gamma; TNF-a: Tumor necrosis factor-a; IL: Interleukin; GALT: Gut-associated lymphoid tissue; Bregs: Regulatory B cells; Th: T helper; SLE: Systemic lupus erythematosus; SS: Sjögren's syndrome; SSc: Systemic sclerosis; MS: Multiple sclerosis; NMOSDs: Neuromyelitis optica spectrum disorders; HSCs: Hematopoietic stem cells; BCR: B-cell receptor;T1:Transitional 1;T2:Transitional 2;T3:Transitional 3; PALS: Periarteriolar lymphoid sheath; FM: Follicular mature; MZ: Marginal zone; Btk: Bruton's tyrosine kinase; SPPL2a: Signal-peptide-peptidase-like 2a; BAFF-R, BR3: $B$ cell activating factor receptor; TLR: Toll-like receptor; T2-MZP: Transitional 2-MZ precursor; PD-L1: Programmed cell death-ligand 1; TGF- $\beta$ : Transforming growth factor- $\beta$; iNKT: Invariant nature killer T; TACl: Transmembrane activator and CAML interactor; BCMA: B cell maturation antigen; NIK: NF-KB-inducing kinase; EAE: Experimental autoimmune encephalomyelitis; CNS: Central nervous system; TNFR: Tumor necrosis factor receptor; ST6GaL-1: ST6Betagalactosamide alpha-2,3-sialyltransferase 1; AIRDs: Autoimmune rheumatic diseases; IFN: Interferon; Clonal IgG: Oligoclonal bands; CIS: Clinically isolated syndrome; LETM: Longitudinally extensive transverse myelitis; ON: Optic neuritis; AQP4-Ab: Aquaporin-4 antibody; BM: Bone marrow; PB: Peripheral blood; CB: Cord blood.
\end{abstract}

\section{Acknowledgements}

Not applicable.

\section{Authors' contributions}

$\mathrm{ZY}$ and $\mathrm{ZY}$ contributed equally to drafting the manuscript. $\mathrm{HJ}, \mathrm{YM}$ and ZJ reviewed the literature, proofread and revised the manuscript. JT designed and supervised the study. All authors read and approved the final manuscript.

\section{Funding}

This work was supported by grants from the General Program of the National Natural Science Foundation of China (No. 81671177), Natural Science Foundation of Jilin Province Science and Technology Development Plan Project (20190201043JC), the Technology Innovation Program of Jilin Provincial Health and Family Planning Commission of China (No. 2016J040), as well as the grants from the Swedish Research Council (No. 2015-03005) and grants from the First hospital, Jilin University of China.

\section{Availability of data and materials}

Not applicable.

\section{Ethics approval and consent to participate}

Not applicable.

\section{Consent for publication}

Not applicable.

\section{Competing interests}

The authors declare that there is no conflict of interests regarding the publication of this paper.

\section{Author details}

${ }^{1}$ Department of Neurology and Neuroscience Center, The First Hospital of Jilin University, Xinmin Street 71\#, Changchun 130021, China. ${ }^{2}$ Department of Neurobiology, Care Sciences and Society, Karolinska Institute, Stockholm, Sweden

Received: 14 January 2020 Accepted: 28 February 2020

Published online: 17 March 2020

\section{References}

1. Oleinika K, Mauri C, Salama AD. Effector and regulatory B cells in immune-mediated kidney disease. Nat Rev Nephrol. 2019;15(1):11-26.

2. Rincon-Arevalo H, Sanchez-Parra CC, Castano D, et al. Regulatory B cells and mechanisms. Int Rev Immunol. 2016;35(2):156-76.

3. Vossenkamper A, Blair PA, Safinia N, et al. A role for gut-associated lymphoid tissue in shaping the human B cell repertoire. J Exp Med. 2013;210(9):1665-74.
4. Loder F, Mutschler B, Ray RJ, et al. B cell development in the spleen takes place in discrete steps and is determined by the quality of $B$ cell receptor-derived signals. J Exp Med. 1999;190(1):75-89.

5. Sims GP, Ettinger R, Shirota Y, et al. Identification and characterization of circulating human transitional B cells. Blood. 2005;105(11):4390-8.

6. Marie-Cardine A, Divay F, Dutot I, et al. Transitional B cells in humans: characterization and insight from $B$ lymphocyte reconstitution after hematopoietic stem cell transplantation. Clin Immunol. 2008;127(1):14-25.

7. Agrawal S, Smith SA, Tangye SG, et al. Transitional B cell subsets in human bone marrow. Clin Exp Immunol. 2013;174(1):53-9.

8. Simon Q, Pers JO, Cornec D, et al. In-depth characterization of CD24(high)CD38(high) transitional human B cells reveals different regulatory profiles. J Allergy Clin Immunol. 2016;137(5):1577-1584.e10.

9. Carsetti R, Rosado MM, Wardmann H. Peripheral development of B cells in mouse and man. Immunol Rev. 2004;197:179-91.

10. van Zelm MC, Szczepanski T, van der Burg M, et al. Replication history of B lymphocytes reveals homeostatic proliferation and extensive antigeninduced B cell expansion. J Exp Med. 2007;204(3):645-55.

11. Blair PA, Norena LY, Flores-Borja F, et al. CD19(+)CD24(hi)CD38(hi) B cells exhibit regulatory capacity in healthy individuals but are functionally impaired in systemic Lupus Erythematosus patients. Immunity. 2010;32(1):129-40.

12. Carvajal Alegria G, Gazeau P, Hillion S, et al. Could lymphocyte profiling be useful to diagnose systemic autoimmune diseases? Clin Rev Allergy Immunol. 2017;53(2):219-36.

13. Taher TE, Ong VH, Bystrom J, et al. Association of defective regulation of autoreactive interleukin-6-producing transitional B lymphocytes with disease in patients with systemic sclerosis. Arthr Rheumatol. 2018;70(3):450-61.

14. Piper CJM, Wilkinson MGL, Deakin CT, et al. CD19(+)CD24(hi)CD38(hi) $B$ cells are expanded in juvenile dermatomyositis and exhibit a proinflammatory phenotype after activation through toll-like receptor 7 and interferon-alpha. Front Immunol. 2018;9:1372.

15. Lee-Chang C, Top I, Zephir H, et al. Primed status of transitional B cells associated with their presence in the cerebrospinal fluid in early phases of multiple sclerosis. Clin Immunol. 2011;139(1):12-20.

16. Quan C, Yu H, Qiao J, et al. Impaired regulatory function and enhanced intrathecal activation of B cells in neuromyelitis optica: distinct from multiple sclerosis. Mult Scler. 2013;19(3):289-98.

17. Cagigi A, Palma P, Nilsson A, et al. The impact of active HIV-1 replication on the physiological age-related decline of immature-transitional B-cells in HIV-1 infected children. AIDS. 2010;24(13):2075-80.

18. Holz LE, Yoon JC, Raghuraman S, et al. B cell homeostasis in chronic hepatitis $C$ virus-related mixed cryoglobulinemia is maintained through naive B cell apoptosis. Hepatology. 2012;56(5):1602-10.

19. Bockstal V, Guirnalda P, Caljon G, et al. T. brucei infection reduces B lymphopoiesis in bone marrow and truncates compensatory splenic lymphopoiesis through transitional B-cell apoptosis. PLoS Pathog. 2011;7(6):e1002089.

20. Sandel PC, Monroe JG. Negative selection of immature B cells by receptor editing or deletion is determined by site of antigen encounter. Immunity. 1999;10(3):289-99.

21. Allman D, Srivastava B, Lindsley RC. Alternative routes to maturity: branch points and pathways for generating follicular and marginal zone B cells. Immunol Rev. 2004;197:147-60.

22. Hardy RR, Hayakawa K. B cell development pathways. Annu Rev Immunol. 2001;19:595-621.

23. Su TT, Rawlings DJ. Transitional B lymphocyte subsets operate as distinct checkpoints in murine splenic B cell development. J Immunol. 2002;168(5):2101-10.

24. Mebius RE, Kraal G. Structure and function of the spleen. Nat Rev Immunol. 2005;5(8):606-16.

25. Henderson RB, Grys K, Vehlow A, et al. A novel Rac-dependent checkpoint in B cell development controls entry into the splenic white pulp and cell survival. J Exp Med. 2010;207(4):837-53.

26. Petro JB, Gerstein RM, Lowe J, et al. Transitional type 1 and 2 B lymphocyte subsets are differentially responsive to antigen receptor signaling. J Biol Chem. 2002;277(50):48009-19.

27. Hamilton JA, Hsu HC, Mountz JD. Autoreactive B cells in SLE, villains or innocent bystanders? Immunol Rev. 2019;292:120-38. 
28. Chung JB, Silverman M, Monroe JG. Transitional B cells: step by step towards immune competence. Trends Immunol. 2003;24(6):342-8.

29. Benitez A, Weldon AJ, Tatosyan L, et al. Differences in mouse and human nonmemory B cell pools. J Immunol. 2014;192(10):4610-9.

30. Allman D, Lindsley RC, Demuth W, et al. Resolution of three nonproliferative immature splenic $B$ cell subsets reveals multiple selection points during peripheral B cell maturation. J Immunol. 2001;167(12):6834-40.

31. Saijo K, Schmedt C, Su IH, et al. Essential role of Src-family protein tyrosine kinases in NF-KB activation during B cell development. Nat Immunol. 2003;4(3):274-9.

32. Niiro H, Clark EA. Regulation of B-cell fate by antigen-receptor signals. Nat Rev Immunol. 2002;2(12):945-56.

33. Huttl S, Klasener K, Schweizer M, et al. Processing of CD74 by the intramembrane protease SPPL2a is critical for B cell receptor signaling in transitional B cells. J Immunol. 2015;195(4):1548-63.

34. Sasaki Y, Casola S, Kutok JL, et al. TNF family member B cell-activating factor (BAFF) receptor-dependent and -independent roles for BAFF in B cell physiology. J Immunol. 2004;173(4):2245-52.

35. Gross JA, Dillon SR, Mudri S, et al. TACI-Ig neutralizes molecules critical for B cell development and autoimmune disease. Impaired B cell maturation in mice lacking BLyS. Immunity. 2001;15(2):289-302.

36. Rowland SL, Leahy KF, Halverson R, et al. BAFF receptor signaling aids the differentiation of immature B cells into transitional B cells following tonic BCR signaling. J Immunol. 2010;185(8):4570-81.

37. Tussiwand R, Rauch M, Fluck LA, et al. BAFF-R expression correlates with positive selection of immature B cells. Eur J Immunol. 2012:42(1):206-16.

38. Carsetti R, Kohler G, Lamers MC. Transitional B cells are the target of negative selection in the B cell compartment. J Exp Med. 1995;181(6):2129-40.

39. Wang H, Feng J, Qi CF, et al. Transitional B cells lose their ability to receptor edit but retain their potential for positive and negative selection. $J$ Immunol. 2007;179(11):7544-52.

40. Wang $\mathrm{H}, \mathrm{Clarke} \mathrm{SH}$. Evidence for a ligand-mediated positive selection signal in differentiation to a mature B cell. J Immunol. 2003;171(12):6381-8.

41. Stadanlick JE, Cancro MP. BAFF and the plasticity of peripheral B cell tolerance. Curr Opin Immunol. 2008;20(2):158-61.

42. Zikherman J, Parameswaran R, Weiss A. Endogenous antigen tunes the responsiveness of naive B cells but not T cells. Nature. 2012;489(7414):160-4.

43. Meyer-Bahlburg A, Andrews SF, Yu KO, et al. Characterization of a late transitional B cell population highly sensitive to BAFF-mediated homeostatic proliferation. J Exp Med. 2008;205(1):155-68.

44. Kolhatkar NS, Brahmandam A, Thouvenel CD, et al. Altered BCR and TLR signals promote enhanced positive selection of autoreactive transitional B cells in Wiskott-Aldrich syndrome. J Exp Med. 2015;212(10):1663-77.

45. Vossenkamper A, Spencer J. Transitional B cells: how well are the checkpoints for specificity understood? Arch Immunol Ther Exp (Warsz). 2011;59(5):379-84.

46. Pieper K, Grimbacher B, Eibel H. B-cell biology and development. J Allergy Clin Immunol. 2013;131(4):959-71.

47. Suryani S, Tangye SG. Therapeutic implications of advances in our understanding of transitional B-cell development in humans. Expert Rev Clin Immunol. 2010;6(5):765-75.

48. Suryani S, Fulcher DA, Santner-Nanan B, et al. Differential expression of CD21 identifies developmentally and functionally distinct subsets of human transitional B cells. Blood. 2010;115(3):519-29.

49. Wardemann H, Yurasov S, Schaefer A, et al. Predominant autoantibody production by early human B cell precursors. Science. 2003;301(5638):1374-7.

50. Palanichamy A, Barnard J, Zheng B, et al. Novel human transitional B cell populations revealed by B cell depletion therapy. J Immunol. 2009;182(10):5982-93.

51. Cheng Y, Sun L, Xie Z, et al. Diversity of immune cell types in multiple sclerosis and its animal model: pathological and therapeutic implications. J Neurosci Res. 2017;95(10):1973-83.

52. Han J, Sun L, Wang $Z$, et al. Circulating regulatory $B$ cell subsets in patients with neuromyelitis optica spectrum disorders. Neurol Sci. 2017:38(7):1205-12.
53. Han J, Sun L, Fan X, et al. Role of regulatory b cells in neuroimmunologic disorders. J Neurosci Res. 2016;94(8):693-701.

54. Iwata Y, Matsushita T, Horikawa M, et al. Characterization of a rare IL10-competent B-cell subset in humans that parallels mouse regulatory B10 cells. Blood. 2011;117(2):530-41.

55. Matsumoto M, Baba A, Yokota T, et al. Interleukin-10-producing plasmablasts exert regulatory function in autoimmune inflammation. Immunity. 2014;41(6):1040-51.

56. Hasan MM, Thompson-Snipes L, Klintmalm G, et al. CD24(hi)CD38(hi) and CD24(hi)CD27(+) human regulatory B cells display common and distinct functional characteristics. J Immunol. 2019;203(8):2110-20.

57. Chung JB, Sater RA, Fields ML, et al. CD23 defines two distinct subsets of immature B cells which differ in their responses to T cell help signals. Int Immunol. 2002;14(2):157-66.

58. Cuss AK, Avery DT, Cannons JL, et al. Expansion of functionally immature transitional B cells is associated with human-immunodeficient states characterized by impaired humoral immunity. J Immunol. 2006;176(3):1506-16.

59. Evans JG, Chavez-Rueda KA, Eddaoudi A, et al. Novel suppressive function of transitional $2 \mathrm{~B}$ cells in experimental arthritis. J Immunol. 2007;178(12):7868-78.

60. Matsushita T, Yanaba K, Bouaziz JD, et al. Regulatory B cells inhibit EAE initiation in mice while other B cells promote disease progression. J Clin Invest. 2008;118(10):3420-30.

61. Carter NA, Vasconcellos R, Rosser EC, et al. Mice lacking endogenous IL-10-producing regulatory $B$ cells develop exacerbated disease and present with an increased frequency of Th1/Th17 but a decrease in regulatory T cells. J Immunol. 2011;186(10):5569-79.

62. Carter NA, Rosser EC, Mauri C. Interleukin-10 produced by B cells is crucial for the suppression of Th17/Th1 responses, induction of T regulatory type 1 cells and reduction of collagen-induced arthritis. Arthritis Res Ther. 2012;14(1):R32.

63. Nova-lamperti E, Fanelli G, Becker PD, et al. IL-10-produced by human transitional B-cells down-regulates CD86 expression on B-cells leading to inhibition of CD4+ T-cell responses. Sci Rep. 2016:6:20044.

64. Flores-borja F, Bosma A, Ng D, et al. CD19+ CD24hiCD38hi B cells maintain regulatory $T$ cells while limiting $\mathrm{TH} 1$ and $\mathrm{TH} 17$ differentiation. Sci Transl Med. 2013;5(173):173ra23.

65. Bosma A, Abdel-Gadir A, Isenberg DA, et al. Lipid-antigen presentation by $C D 1 d(+) B$ cells is essential for the maintenance of invariant natural killer T cells. Immunity. 2012;36(3):477-90.

66. Khan AR, Hams E, Floudas A, et al. PD-L1hi B cells are critical regulators of humoral immunity. Nat Commun. 2015;6:5997.

67. Burton $\mathrm{H}$, Dorling A. Transitional B cell subsets-a convincing predictive biomarker for allograft loss? Kidney Int. 2017;91(1):18-20.

68. Liu M, Guo Q, Wu C, et al. Type I interferons promote the survival and proinflammatory properties of transitional B cells in systemic lupus erythematosus patients. Cell Mol Immunol. 2019;16(4):367-79.

69. Korn T, Bettelli E, Gao W, et al. IL-21 initiates an alternative pathway to induce proinflammatory $\mathrm{T}(\mathrm{H}) 17$ cells. Nature. 2007;448(7152):484-7.

70. Lino AC, Dorner T, Bar-Or A, et al. Cytokine-producing B cells: a translational view on their roles in human and mouse autoimmune diseases. Immunol Rev. 2016:269(1):130-44.

71. Mackay F, Schneider P. Cracking the BAFF code. Nat Rev Immunol. 2009:9(7):491-502.

72. Lesley R, Xu Y, Kalled SL, et al. Reduced competitiveness of autoantigenengaged B cells due to increased dependence on BAFF. Immunity. 2004;20(4):441-53.

73. Cancro MP. Peripheral B-cell maturation: the intersection of selection and homeostasis. Immunol Rev. 2004;197:89-101.

74. Varin MM, le Pottier $L$, Youinou P, et al. B-cell tolerance breakdown in Sjogren's syndrome: focus on BAFF. Autoimmun Rev. 2010;9(9):604-8.

75. Schiemann B, Gommerman JL, Vora K, et al. An essential role for BAFF in the normal development of B cells through a BCMA-independent pathway. Science. 2001;293(5537):2111-4.

76. Tarique $\mathrm{M}, \mathrm{Naz} \mathrm{H}$, Kurra SV, et al. Interleukin-10 producing regulatory B cells transformed CD4(+)CD25(-) into tregs and enhanced regulatory T cells function in human leprosy. Front Immunol. 2018;9:1636.

77. Granato A, Hayashi EA, Baptista BJ, et al. IL-4 regulates Bim expression and promotes $B$ cell maturation in synergy with BAFF conferring 
resistance to cell death at negative selection checkpoints. J Immunol. 2014;192(12):5761-75

78. Nelms K, Keegan AD, Zamorano J, et al. The IL-4 receptor: signaling mechanisms and biologic functions. Annu Rev Immunol. 1999;17:701-38.

79. Mihara M, Hashizume M, Yoshida H, et al. IL-6/IL-6 receptor system and its role in physiological and pathological conditions. Clin Sci (Lond). 2012;122(4):143-59.

80. Hunter CA, Jones SA. IL-6 as a keystone cytokine in health and disease. Nat Immunol. 2015:16(5):448-57.

81. Bettelli E, Carrier Y, Gao W, et al. Reciprocal developmental pathways for the generation of pathogenic effector TH17 and regulatory T cells. Nature. 2006:441(7090):235-8.

82. Acosta-Rodriguez EV, Napolitani G, Lanzavecchia A, et al. Interleukins $1 \beta$ and 6 but not transforming growth factor- $\beta$ are essential for the differentiation of interleukin 17-producing human Thelper cells. Nat Immunol. 2007;8(9):942-9.

83. Serada S, Fujimoto M, Mihara M, et al. IL-6 blockade inhibits the induction of myelin antigen-specific Th17 cells and Th1 cells in experimental autoimmune encephalomyelitis. Proc Natl Acad Sci USA. 2008;105(26):9041-6.

84. Karnell JL, Rieder SA, Ettinger R, et al. Targeting the CD40-CD40L pathway in autoimmune diseases: humoral immunity and beyond. Adv Drug Deliv Rev. 2018;141:92-103.

85. Lemoine S, Morva A, Youinou P, et al. Human T cells induce their own regulation through activation of B cells. J Autoimmun. 2011;36(3-4):228-38.

86. Fillatreau S, Sweenie CH, McGeachy MJ, et al. B cells regulate autoimmunity by provision of IL-10. Nat Immunol. 2002;3(10):944-50.

87. Qian Y, Qin J, Cui G, et al. Act1, a negative regulator in CD40- and BAFF-mediated B cell survival. Immunity. 2004;21(4):575-87.

88. Qian Y, Giltiay N, Xiao J, et al. Deficiency of Act1, a critical modulator of B cell function, leads to development of Sjogren's syndrome. Eur J Immunol. 2008:38(8):2219-28.

89. Giltiay NV, Lu Y, Allman D, et al. The adaptor molecule Act1 regulates BAFF responsiveness and self-reactive $B$ cell selection during transitional $B$ cell maturation. J Immunol. 2010;185(1):99-109.

90. Nasirikenari M, Chandrasekaran EV, Matta KL, et al. Altered eosinophil profile in mice with ST6Gal-1 deficiency: an additional role for ST6Gal-1 generated by the P1 promoter in regulating allergic inflammation. J Leukoc Biol. 2010;87(3):457-66

91. Nasirikenari M, Segal BH, Ostberg JR, et al. Altered granulopoietic profile and exaggerated acute neutrophilic inflammation in mice with targeted deficiency in the sialyltransferase ST6Gal I. Blood. 2006;108(10):3397-405.

92. Dougher CWL, Buffone A Jr, Nemeth MJ, et al. The blood-borne sialyltransferase ST6Gal-1 is a negative systemic regulator of granulopoiesis. J Leukoc Biol. 2017:102(2):507-16.

93. Irons EE, Lau JTY. Systemic ST6Gal-1 is a pro-survival factor for murine transitional B cells. Front Immunol. 2018:9:2150.

94. Hennet T, Chui D, Paulson JC, et al. Immune regulation by the ST6Gal sialyltransferase. Proc Natl Acad Sci USA. 1998;95(8):4504-9.

95. Marth JD. Unmasking connections in transmembrane immune signaling. Nat Immunol. 2004;5(10):1008-10.

96. Dieudonne Y, Gies V, Guffroy A, et al. Transitional B cells in quiescent SLE: An early checkpoint imprinted by IFN. J Autoimmun. 2019;102:150-8.

97. Clarke AJ, Ellinghaus $\mathrm{U}$, Cortini A, et al. Autophagy is activated in systemic lupus erythematosus and required for plasmablast development. Ann Rheum Dis. 2015:74(5):912-20.

98. Barr TA, Shen P, Brown S, et al. B cell depletion therapy ameliorates autoimmune disease through ablation of IL-6-producing B cells. J Exp Med. 2012:209(5):1001-10.

99. Machado-Santos J, Saji E, Troscher AR, et al. The compartmentalized inflammatory response in the multiple sclerosis brain is composed of tissueresident CD8+ Tlymphocytes and B cells. Brain. 2018;141(7):2066-82.

100. Baker D, Pryce G, Amor S, et al. Learning from other autoimmunities to understand targeting of $\mathrm{B}$ cells to control multiple sclerosis. Brain. 2018:141(10):2834-47.

101. Milo R. Therapeutic strategies targeting B-cells in multiple sclerosis. Autoimmun Rev. 2016;15(7):714-8.

102. D'amico E, Zanghi A, Gastaldi M, et al. Placing CD20-targeted B cell depletion in multiple sclerosis therapeutic scenario: present and future perspectives. Autoimmun Rev. 2019:18:665-72.

103. Baecher-Allan C, Kaskow BJ, Weiner HL. Multiple sclerosis: mechanisms and Immunotherapy. Neuron. 2018:97(4):742-68.
104. Jelcic I, Al Nimer F, Wang J, et al. Memory B cells activate brain-homing, autoreactive CD4(+) T cells in multiple sclerosis. Cell. 2018;175(1):85-100. e23.

105. von Budingen HC, Bar-Or A, Zamvil SS. B cells in multiple sclerosis: connecting the dots. Curr Opin Immunol. 2011;23(6):713-20.

106. Hausler D, Hausser-Kinzel S, Feldmann L, et al. Functional characterization of reappearing $B$ cells after anti-CD20 treatment of CNS autoimmune disease. Proc Natl Acad Sci USA. 2018;115(39):9773-8.

107. Biragyn A, Aliseychik M, Rogaev E. Potential importance of B cells in aging and aging-associated neurodegenerative diseases. Semin Immunopathol. 2017;39(3):283-94.

108. Li R, Patterson KR, Bar-Or A. Reassessing B cell contributions in multiple sclerosis. Nat Immunol. 2018;19(7):696-707.

109. Matsushita T, Horikawa M, Iwata Y, et al. Regulatory B cells (B10 cells) and regulatory $T$ cells have independent roles in controlling experimental autoimmune encephalomyelitis initiation and late-phase immunopathogenesis. J Immunol. 2010;185(4):2240-52.

110. Giacomini E, Rizzo F, Etna MP, et al. Thymosin-alpha1 expands deficient IL-10-producing regulatory B cell subsets in relapsing-remitting multiple sclerosis patients. Mult Scler. 2018:24(2):127-39.

111. MiyazakiY,Niino M, Fukazawa T, et al. Suppressed pro-inflammatory properties of circulating B cells in patients with multiple sclerosis treated with fingolimod, based on altered proportions of B-cell subpopulations. Clin Immunol. 2014;151(2):127-35.

112. Yoshizaki A, Miyagaki T, Dilillo DJ, et al. Regulatory B cells control T-cell autoimmunity through IL-21-dependent cognate interactions. Nature. 2012:491(7423):264-8.

113. Ries S, Hilgenberg E, Lampropoulou V, et al. B-type suppression: a role played by "regulatory B cells" or "regulatory plasma cells"? Eur J Immunol. 2014;44(5):1251-7.

114. Nielsen $\mathrm{CH}$, Bornsen L, Sellebjerg F, et al. Myelin basic protein-induced production of tumor necrosis factor-alpha and interleukin-6, and presentation of the immunodominant peptide MBP85-99 by B cells from patients with relapsing-remitting multiple sclerosis. PLOS ONE. 2016;11(1):e0146971.

115. WingerchukDM, LennonVA, Lucchinetti CF, et al. The spectrum of neuromyelitis optica. Lancet Neurol. 2007;6(9):805-15.

116. Drori T, Chapman J. Diagnosis and classification of neuromyelitis optica (Devic's syndrome). Autoimmun Rev. 2014;13(4-5):531-3.

117. Chihara N, Aranami T, Sato W, et al. Interleukin 6 signaling promotes antiaquaporin 4 autoantibody production from plasmablasts in neuromyelitis optica. Proc Natl Acad Sci USA. 2011:108(9):3701-6.

118. Jarius S, Wildemann B. AQP4 antibodies in neuromyelitis optica: diagnostic and pathogenetic relevance. Nat Rev Neurol. 2010;6(7):383-92.

119. Lennon VA, Wingerchuk DM, Kryzer TJ, et al. A serum autoantibody marker of neuromyelitis optica: distinction from multiple sclerosis. Lancet. 2004:364(9451):2106-12.

120. Han J, Yang MG, Zhu J, et al. Complexity and wide range of neuromyelitis optica spectrum disorders: more than typical manifestations. Neuropsychiatr Dis Treat. 2017;13:2653-60.

121. Wang H, Wang K, Zhong X, et al. Cerebrospinal fluid BAFF and APRIL levels in neuromyelitis optica and multiple sclerosis patients during relapse. J Clin Immunol. 2012:32(5):1007-11.

122. Cotzomi E, Stathopoulos P, Lee CS, et al. Early B cell tolerance defects in neuromyelitis optica favour anti-AQP4 autoantibody production. Brain. 2019;142(6):1598-615.

123. Quan C, Zhangbao J, Lu J, et al.The immune balance between memory and regulatory B cells in $\mathrm{NMO}$ and the changes of the balance after methylprednisolone or rituximab therapy. J Neuroimmunol. 2015;282:45-53.

124. Krumbholz M, Meinl E. B cells in MS and NMO: pathogenesis and therapy. Semin Immunopathol. 2014;36(3):339-50.

\section{Publisher's Note}

Springer Nature remains neutral with regard to jurisdictional claims in published maps and institutional affiliations. 